\title{
La audaz intelectualidad afro de Teófilo Potes*
}

DOI: https://doi.org/10.18046/recs.i3o.3514

The Audacious Black Intellectualism of Teófilo Potes Michael Birenbaum-Quintero**

Universidad de Boston (Boston, Estados Unidos)

\footnotetext{
* Este artículo es un aparte de un trabajo de investigación realizado con Lucymar Bolaños y Hebert Hurtado, y con la valiosa participación de las personas entrevistadas. Componentes de esta investigación se hicieron con apoyo de las becas Fulbright Core Scholars Fellowship, 2013-14. Artículo de investigación recibido el 15.02.2019 y aceptado el 20.12.2019.

** Doctor y magíster en Etnomusicología por la Universidad de Nueva York (Estados Unidos). Profesor titular de Musicología y Etnomusicología y profesor titular afiliado de Estudios Afroamericanos y Estudios Latinoamericanos de la Universidad de Boston (Estados Unidos).Correo electrónico:mbq@bu.edu ORCID: http://orcid.org/oooo-ooo1-5511-3203
} 


\section{Cómo citar/How to cite}

Birenbaum-Quintero, Michael (2020). La audaz intelectualidad afro de Teófilo Potes.

Revista CS, 30, 97-122. https://doi.org/10.18046/recs.i30.3514 


\section{Resumen}

Teófilo Roberto Potes es una figura clave en la historia del Pacífico colombiano, pero poco se aprecian su importancia y complejidad hoy en día. El presente artículo sugiere que la vida y obra de Potes ameritan reconsiderarse hoy. Utilizando fuentes orales de sus discípulos, fuentes primarias y una ignorada publicación de él mismo; y contextualizándolos en su momento, se reconstruye la biografía de Potes y se esbozan los principales elementos de su pensamiento. Así se da cuenta de la importancia de un personaje que, incluso más allá de ser el primero en valorizar y mostrar la cultura afropacífica, da luces de un concepto de la intelectualidad afro, de la herencia africana, del contenido político de la cultura y de una radical horizontalidad entre lo occidental y lo afropacífico, para considerar en la coyuntura actual.

PALABRAS CLAVE:

intelectuales, afrocolombianos, folclor, Teófilo Roberto Potes

Teófilo Roberto Potes is a central figure in the history of the Colombian Pacific region, but his importance and complexity are poorly understood today. The present article suggests that Potes' life and work merit reconsideration today. By using oral histories of his students, primary sources, and an unknown publication of Potes himself, and by contextualizing them in their moment, the article reconstructs Potes' biography and sketches the principal elements of his thought. In that way, it traces the importance of a person who, even beyond being the first one to valorize and reveal the Afro-Pacific culture, demonstrates a concept of the African heritage, of the political component of culture, of being a black intellectual, and of the radical horizontality of the Western and Afro-Pacific worlds to be considered in the present historical conjuncture.

\section{KEYWORDS:}

Intellectuals, Afro-Colombians, Folklore, Teófilo Roberto Potes 



\section{Dedicado al legado cimarrón de Alicia Camacho Garcés.}

Ìbà' è̀ bà ẹni, tó nù

\section{Introducción}

La historia de Colombia está repleta de eruditos: presidentes gramáticos, generales poetas, sacerdotes botánicos, hacendados folcloristas. Reconocer y cuestionar un punto obvio -que dichos personajes también fueron, casi en su totalidad, hombres blancos pudientes- empieza a revelar una verdad fundamental para entender el país: que en la conformación de la intelectualidad en Colombia están las mismas raíces históricas no solamente del saber, sino del poder. La figura fundacional de la "ciudad letrada", descrita por el crítico uruguayo Ángel Rama, no es una "ciudad de letras". Es decir, las sociedades latinoamericanas no son sociedades donde el pueblo ha tenido acceso al poder de la palabra escrita; más bien el poder de la palabra que regía en esas ciudades civilizadoras y que autorizaba su papel de dominación sobre los territorios y sus gentes fue privilegio exclusivo de los pocos letrados (Chasteen, 1996; Rama, 1984). Cristina Rojas (2001) argumenta que, en el caso colombiano específicamente, la élite decimonónica fue relativamente pobre y geográficamente dispersa en comparación con las de otros países latinoamericanos; lo que cimentaba su dominio fue ser letrados en un país analfabeta:

En la Colombia de mediados del siglo XIX, la economía política no estaba centrada en la acumulación de riquezas sino en la acumulación de palabras y capital civilizador. El poder se concentraba en quienes poseían los secretos de la civilización occidental: los hombres criollos letrados, que se reservaron su propio lugar en el régimen de representación, pues eran los únicos que poseían el conocimiento necesario para dirigir la nueva república por la ruta apropiada (...). Los letrados fueron los arquitectos de la civilización y su poder estaba cimentado en su capacidad para producir, circular y valorizar su bien más preciado: las palabras. (140)

Y es precisamente sobre la palabra escrita en su sentido más estrecho, más inaccesible, que se establece el ilusorio "punto cero" -objetivo, absoluto, racional, perfecto, irrefutable- desde el cual los ilustrados y letrados criollos presumían disciplinar el mundo a su alrededor (Castro-Gómez, 2005). No se trata de una disciplina solamente discursiva. ¿Cómo es que reza el dicho? "La letra con sangre entra” (Deas, 1993: 45; Rojas, 2001). Esta disposición del poder-saber, entonces, no solamente limita cualquier propósito de una intelectualidad o contra-saber, ya sea afro, indígena o no-masculino, es diseñada precisamente para imposibilitarlo. 
Ni el protofolclorismo de los costumbristas conservadores ni la más tardía reconfiguración de lo popular en el truncado período populista de la República Liberal perturbó este orden. Los costumbristas reflejaban su idealización nostálgica de un paternalismo rural armonioso en que los campesinos se mantenían libres de pensamientos modernos o ínfulas de ciudadanía (Bermúdez-Escobar, 2007; Deas, 1993; Sommer, 1991), mientras que el proyecto liberal se debatía entre un proceso civilizatorio que buscaba modernizar las masas exponiéndoles a la cultura "universal" y un proceso de valoración de la cultura popular (rural) como un substrato nacional que para dar frutos necesitaba "corrección" y domesticación a patrones estéticos occidentales (Birenbaum-Quintero, 2018; Muñoz, 2014; Silva, 2005;Zapata-Cortés, 2009). En el mejor de los casos, como en la fundación de la antropología nacional o en algunas políticas culturales, las prácticas populares llegaron a ser objeto de estudio, u objeto de estilización, pero en ningún caso fueron entendidas como saberes en sí. Y de todos modos lo afro-relegado al folclor (cuando no a los medios masivos) más que a la antropología, y visto como una falta de civilización más que la presencia viva de una cultura- apenas tenía dónde figurar en el campo, en sí ya precario, de lo popular (Arboleda-Quiñonez, 2011; Birenbaum-Quintero, 2018; Caicedo-Ortiz, 2013; Echeverri, 1997).

En este desolador contexto, es notable el surgimiento, aproximadamente a mitad del siglo XX, de una cohorte de destacados intelectuales afrocolombianos, incluyendo, entre otros, a Jorge Artel (1909-1994), Diego Luis Córdoba (1907-1954), Natanael Díaz (1919-1964), Aquiles Escalante (1923-2002), Helcías Martán-Góngora (19201984), Teresa Martínez de Varela (1913-1998), Arnoldo Palacios (1924-2015), Rogerio Velásquez (1908-1965), Delia Zapata-Olivella (1926-2001), Manuel Zapata-Olivella (1920-2004) y Teófilo Roberto Potes (1917-1975). Entre estas eminencias, Potes es un caso un poco aparte. No fue político o poeta o novelista, como algunos de sus contemporáneos; y no se le conoce ningún estudio antropológico. Guarda más similitud con la también coreógrafa Delia Zapata-Olivella, pero publicó mucho menos; de hecho, en vida no publicó ningún escrito, el sine qua non para la intelectualidad colombiana, y de los dos artículos póstumos de su autoría, uno es la transcripción de un discurso y el otro una recopilación de fragmentos.

Eso sí hay que reconocer: la emergencia de la cultura del Pacífico de las veredas ribereñas a la conciencia nacional y, cada día más, internacional, se debe en gran parte a Potes. Fue él la primera persona en llevar la danza y la música del Pacífico Sur a la tarima. Recuerdan algunos que fueron discípulos de Potes:

Antes de Teófilo, no había nada. Y antes de Teófilo no había nadie. Y cuando sale Teófilo (...) hasta ese momento no había currulao como danza. Hay un montón de gente que baila en sus casas... pero nada de coreografía. Es Teófilo Potes. Él hace la coreografía... 
Y [dice], “esto hay que ponerlo aquí, esto va allá, y la organiza. Y luego lo ponen a bailar. (Hugo Montenegro Manyoma, comunicación personal, 2005)

Y Teófilo inclusive, (...) por ser tan orgulloso, dedicado a defender al Pacífico, de lo valioso que era esto, él fue, y se puede decir que en Colombia, [quien] organizó un grupo de danza para llevar eso a los escenarios. Nadie en Colombia estaba en eso, fue Teófilo R. Potes. (Alicia Camacho', comunicación personal, 2013)

En nuestra época, la música y danza del Pacífico, así como la herencia africana en Colombia son postulados como patrimonio cultural de una forma muchas veces folclorizante ${ }^{2}$. Pero al menos se las reconoce como música, danza y cultura, y no como un desbordante caos sonoro, corporal y social. A mediados del siglo XX, imaginar que la música y danza afropacíficas -por muchos años entendidas como vergonzosa evidencia de lo racialmente inferior y moralmente inadecuado para el modelo de modernidad imperante-fueran expresiones no para esconder o extirpar, sino para entarimar, y mostrar al país y al mundo, era una idea bastante radical.

Pero además de talentoso coreógrafo, Teófilo Potes fue un hombre culto, hasta en el sentido más excluyente de la palabra. Conocía casi todos los países de América, hablaba varios idiomas europeos con fluidez-además de lenguas indígenas del Pacífico-y fue un lector voraz y bien informado. Había estudiado en uno de los mejores colegios del país en su época, el Santa Librada en Cali, y trabajaba de docente en el reconocido Pascual de Andagoya (entre otros) en Buenaventura. Descalzo o en sandalias, en su infaltable atuendo blanco de un humilde pescador, en su casa de madera en las afueras del Muro Yusti ${ }^{3}$-modesto barrio de bajamar en Buenaventura- atendía visitas de profesores de la Sorbona, de la Universidad de París, de la Unesco, de Cambridge, de Oxford, de Columbia (Potes, 1975: 14). A veces recibía invitaciones: la argentina Isabel Aretz, directora del Instituto de Etnomusicología y Folklore (INIDEF) en Caracas, semillero de los estudios etnomusicológicos en toda América Latina y el Caribe, había recibido a Potes alrededor de 1970 (Brandt, 1973; Potes, 1975). Max Brandt, un etnomusicólogo estadounidense afiliado con INIDEF

1. Las entrevistas a Alicia Camacho, cantante, compositora, danzante, activista y, en vida, fiel conservadora del legado intelectual de Teófilo R. Potes, se pueden consultar en internet, junto con material relevante sobre su vida (Camacho-Garcés; Camacho; Birenbaum-Quintero; Hurtado, 2014).

2. Dice Santiago Arboleda-Quiñónez (2011: 69): "La folklorización hace parte de este gran movimiento cognitivo europeo global que descontextualizó al 'otro', representándolo de manera sutil ya en el siglo XX como extranjero y/o extemporáneo, siempre atrasado, finalmente pieza de museo, aún en el seno de sus correspondientes naciones".

3. Para algunos, la casa de Potes quedaba en un barrio vecino, Venecia. 
hizo una breve visita a Potes en 1973. El Banco de la República, en Buenaventura, conserva una transcripción de sus notas de campo, donde Brandt (1973) describe a Potes:

Cuando entramos a la casa, el Sr. Potes nos invita al segundo piso, al taller que colindaba con su habitación. Estaba vestido informalmente en ropa blanca de trabajar y pies descalzos. Tiene 56 años, nacido el 2 noviembre. Él es amigo de la dra. Aretz y conoce Caracas. Parece ser muy bien informado sobre la música de la Costa Pacífica y sobre etnomusicología y los orígenes africanos de su gente por lo general. De hecho me impresiona como la persona más inteligente y más informada sobre el tema de la etnomusicología afroamericana que he conocido en Colombia ${ }^{4}$. Tampoco he conocido a un hombre negro en Venezuela que sepa con tanta precisión de su legado africano (...). Tiene una buena colección de libros sobre música, folklore, África, etc. montados uno sobre el otro en su habitación. Cuando preguntamos por los orígenes africanos de un instrumento en particular, nos hizo referencia a uno de sus libros sobre arte africano con una foto del instrumento. (170)

Potes, en su casa sobre palafitas, fue tan intelectual como sus contemporáneos afrocolombianos. Es más, en este artículo se pretende argumentar que la forma de intelectualidad de Potes podría ser la más audaz, la más radical, la más relevante para el presente momento, entre todos sus contemporáneos. Primero, porque Potes entendió que ser intelectual en Colombia es algo así como una performance, un habitus $^{5}$. Consciente de que esa performance giraba en torno no tanto al conocimiento ni a las palabras, sino también al blanqueamiento y al porte burgués, Potes gozaba de interpretar el papel del letrado catedrático a la vez que se burlaba de él. Segundo, para Potes, no valía saber de la gente, o encuadrarla en un esquema epistemológico; lo que valía era el mismo saber popular. De hecho, puso el saber popular como base de las ciencias, dando un giro completo a las jerarquías epistemológicas que conformaban la intelectualidad en el país. Igualmente, más que rupturas epistemológicas, Potes proponía unas complejidades ontológicas que redujeran el saber occidental de un mapamundi a un solo sistema dentro de un multiverso mucho más denso.

Además, en su trabajo coreográfico y folclorista, Potes siempre se pronunció solo sobre la región del Pacífico Sur, a diferencia de figuras como los hermanos Zapata-Olivella, cuyo ámbito fue más amplio. Pero Potes no imaginaba su región dentro del esquema nacionalista de una diversidad regional que conforma un país unido,

\footnotetext{
4. Brandt, unos días antes de hacer este último comentario había visitado, en Bogotá, el museo del Conservatorio de Música de la Universidad Nacional, donde conoció al “folclorólogo" Guillermo Abadía-Morales, viva encarnación del tradicional letrado colombiano.
}

5. Ver Bourdieu (1996; 1997; 1998) y Butler (2009), así como la información presentada más adelante. 
porque su pensamiento fue nutrido por una fuerte corriente afrocentrista, basada en el centro intradiaspórico y no en el folclor nacionalista colombiano, y porque no creía en la democracia racial o el mestizaje amistoso. Viendo su obra maestra, La mina, es claro que para Potes lo que conformaba el país, y la región del Pacífico dentro de ella, fue la dominación y la esclavización a la fuerza.

De la misma forma, Potes vio en los saberes y las prácticas afropacíficos una ruta hacia una liberación epistémica, que traspasaba las limitadas y limitantes fronteras de lo político en la era del Frente Nacional colombiano y la Guerra Fría. Por todas esas razones, además de las críticas a la intelectualidad de la clase letrada colombiana, el enfoque de acción de Potes no fue en las librerías y las universidades-aunque también se nutría de ellas-, sino en los barrios de su Buenaventura. Potes fue, entonces, un letrado que buscaba trascender la palabra escrita, un cosmopolita que escogió quedarse en Buenaventura; es decir, un intelectual audaz afrocolombiano.

\section{Una vida de contrastes}

Teófilo Roberto Potes nació en una vereda de Buenaventura, sobre el río Anchicayá, en 1917. A los 12 años, pasó del Anchicayá a Cali, donde su madre, Felisa Potes, trabajaba de empleada en la casa de una familia acaudalada de apellido Vásquez. El patriarca, impresionado con el muchacho, patrocinó su educación, y Potes estudió en uno de los mejores colegios del país, el Santa Librada. Inclusive cursaba estudios universitarios de medicina, que quedaron inconclusos por la muerte de su benefactor ${ }^{6}$.

Potes (1975: 13) dataría sus inicios en el folclor durante el año 1938, cuando tenía veintiocho años; la fecha parece coincidir, aproximadamente, con la indeseada terminación de su carrera académica, cuando pasó a trabajar como inspector en el Pacífico rural. El oficio lo llevó, como representante del Estado, a las apartadas comunidades de los ríos del Pacífico. Viajaba de vereda en vereda resolviendo problemas, investigando y castigando crímenes, y probablemente utilizando su entrenamiento médico. Se puede imaginar en ese período un encuentro de saberes, que resultaría central en su forma de pensar, entre las prácticas médicas y espirituales recordadas de su niñez en el Anchicayá, y el pensamiento y la medicina occidentales que había estudiado en Cali y que él representaba en su oficio de inspector.

Parece también que Potes estaba haciendo algún tipo de investigación etnográfica y hasta archivística, sin tener formación metodológica. Durante una visita oficial como inspector al pueblo de Iscuandé (Nariño), Potes compró una barra de jabón

6. Es interesante que Abadía Morales y Manuel Zapata-Olivella también estudiaron medicina, para terminar en el folclor después de una residencia rural. 
de un tendero local, quien la envolvió en un trozo de papel viejo que le llamó la atención, así que decidió comprar los papeles de envoltura. Estos resultaron ser un documento del año 1828 que describía una revuelta de esclavizados en el río Iscuandé, firmado por la mano del entonces gobernador y futuro presidente Tomás Cipriano de Mosquera (1798-1878). Años después, los eventos descritos en ese documento inspirarían la obra maestra de Potes, La Mina (Potes, 1975).

Posteriormente, Potes viajó a Estados Unidos, tal vez en más de una ocasión, durante la década de 1940, buscando trabajo (Alicia Camacho, comunicación personal, 2013). Habría sido en la ciudad de Nueva York donde se encontró con una persona que marcaría su vida: Katherine Dunham (1909-2006). Dunham, afroamericana de Chicago, fue una renombrada coreógrafa y danzante, cuyo grupo de danza hizo giras por el mundo y salía en películas. También fue antropóloga, habiendo estudiado con Melville Herskovits, el antropólogo y progenitor de estudios afro, en los años treinta. Fue de sus investigaciones etnográficas entre poblaciones afro en el Caribe, y sobre todo en Haití (donde viviría por muchos años e inclusive se iniciaría como sacerdotisa en el voduismo), que derivó su “Técnica Dunham", un método corporal basado en las danzas afrocaribeñas que revolucionó la danza moderna y que se sigue estudiando hoy en día. Sus coreografías, que para la época incluían representaciones de danzas de las poblaciones afro de Estados Unidos, Cuba, Martinica, Jamaica, Haití y Trinidad, entre otras, fueron insumos de su trabajo de campo -algo similar a una "etnografía representada" (Clark, 2005).

En el verano de 1950, Dunham salió en su primera gira por Suramérica, patrocinada por el Gobierno de Estados Unidos. Aparentemente, llevó en la compañía a Teófilo Potes. Fue una gira con muchos acontecimientos. Estuvieron varios meses en Belém do Pará y Río de Janeiro en Brasil, donde Potes engendró un hijo, João (Alicia Camacho, comunicación personal, 2013). En São Paulo, un reconocido hotel le negó la posada al grupo de Dunham en un acto racista. Dunham llamó la atención de la prensa local, desatando una controversia que resultó en la aprobación, en 1951, de una ley que castigaba la discriminación racial en lugares públicos, en Brasil (Alberto, 2011: 176-178; Andrews, 1991: 184-186).

Poco después, ya en Argentina, donde se presentaron ante Evita Perón y compartieron con bailadores de tango afroargentinos, el grupo empezó a ensayar una nueva obra colectivamente compuesta con Dunham y sus danzantes (Valis-Hill, 1994). La obra, titulada Southland, fue explícitamente política y antirracista, y cuando fue estrenada en Santiago de Chile, el Departamento de Estado de los Estados Unidos cortó los fondos, suprimió la presentación de la obra y se aseguró de la apresurada salida de la compañía de Chile (Clark, 2005; Valis-Hill, 1994). Potes probablemente acompañó al grupo en las paradas restantes de la gira por Suramérica. 
En febrero de 1951 llegaron a Colombia, presentándose en Cali y, unos días después, en Bogotá, ante un público donde se encontraban Delia y Manuel Zapata-Olivella. Es probable que Potes se haya quedado en Colombia mientras el grupo seguía a Europa y los países del norte de África, pero, según Camacho, Potes sostenía haber visitado Francia, España y África, hecho que probablemente habría tenido lugar durante la subsecuente gira entre 1951 y 1953 . Lo cierto es que ya para mediados de los cincuenta Potes había vuelto a Buenaventura, para vivir permanentemente en su casa de bajamar. Potes,

(...) estando [de gira con Dunham], se pone a analizar. Si esto es folclor, lo que hay en el Pacífico es grandioso. Y entonces ahí renunció y se vino nuevamente con esa idea a organizar acá, a hacer entender a los negros del Pacífico el valor que tenía un tapao [sopa] de pescado. (Alicia Camacho, comunicación personal, 2013)

En Buenaventura, Potes enseñaba en el Colegio Pascual de Andagoya y en el Liceo Femenino del Pacífico. Tenía un programa en Radio Andagoya, en el cual utilizaba su espléndido y resonante barítono para declamar poesía local y latinoamericanista, y disertaba sobre las particularidades del "hombre del Pacífico" (Alicia Camacho, comunicación personal, 2014; Fabio Caicedo, comunicación personal, 2014; Engelberto Díaz, comunicación personal, 2014). En algún momento, empezó a dar cátedra y demostración de la cultura local para turistas, visitas y gente local en un quiosco enramado en el parque del malecón todos los domingos (Medardo Arias-Satizábal, comunicación personal, 2017). Y para finales de la década de los cincuenta, empezaba a organizar su primer grupo de danza, Acuarelas del Pacífico, para la conformación del cual seguía conversando con cultores tradicionales, así como había hecho durante su época de inspector.

Acuarelas del Pacífico fue el primer grupo en componer y presentar coreografías de la música y danza tradicionales del Pacífico, seguido por el emblemático grupo Bahía de la Cruz, patrocinado por Puertos de Colombia en su época. Después que este último grupo terminó por diferencias internas, Potes dirigió el grupo Los Canchimalos y un grupo infantil, Los Canchimalitos. Acuarelas del Pacífico participó en el primer Festival Folclórico de Buenaventura, fundado por el poeta guapireño y entonces alcalde de Buenaventura Helcías Martán-Góngora, en 1962, además de la primera Feria de Manizales en el mismo año. La gran danzante y coreógrafa Mercedes Montaño empezó a bailar formalmente en el grupo de Potes alrededor de 1960 (Alcides Carabalí; Alfonso Portocarrero, comunicación personal, 2005); su grupo también dio inicio a las carreras artísticas de la decimera Margarita Hurtado, y la cantante y compositora Alicia Camacho. 
Fue con Potes y su grupo que los bailarines del grupo de Delia y Manuel Zapata-Olivella aprendieron el danzario del Pacífico, el cual llevaron a Francia, Rusia, China y más allá (Madolia de Diego Parra, comunicación personal, 2009). Y fue con Potes y Montaño que el folclorista Octavio Marulanda hizo las emblemáticas grabaciones para el Instituto Popular de Cultura, amén de Manuel Zapata-Olivella y el etnomusicólogo estadounidense George List. Potes también colaboraba con monseñor Gerardo Valencia Cano, obispo de Buenaventura y precursor de la teología de la liberación. Según algunas fuentes (Alicia Camacho, comunicación personal, 2013) ${ }^{8}$, fueron Teófilo Potes y su grupo quienes protagonizaban las misas culturales o misas afro que llevaron bombos y cununos tradicionales a las iglesias, como parte del proyecto por el que abogaba Valencia-Cano de integrar la religiosidad popular al catolicismo institucional (aunque no fue generalizado hasta la posterior fundación de la Pastoral Afrocolombiana).

Poco después de presentarse en un congreso sobre folclor, en Manizales, a Potes se le descubrió un cáncer avanzado. Volvió a Manizales, donde murió en un hospital. Según Hugo Montenegro-Manyoma (comunicación personal, 2005), quien en ese entonces era un joven bailarín y que vivió con él antes de su muerte, Potes pasaba "largas noches de insomnio, escribiendo y escribiendo en una máquina" en idiomas extranjeros, "para enviar a algunas revistas en Alemania o Norteamérica”. Se rumora que una maleta de libros y escritos de Potes fue llevada a Manizales o Medellín poco antes de su muerte, pero aparte de unos fragmentos publicados por la Universidad de Manizales no se sabe más de su producción escrita.

\section{La intelectualidad como performance}

Santiago Castro-Gómez (2005) ubica la supuesta racionalidad imparcial de la intelectualidad colombiana (y neogranadina) en un habitus, una performance del capital cultural letrado. En su argumento, el habitus ${ }^{9}$-un planteamiento del sociólogo francés Pierre Bourdieu-funciona

\footnotetext{
7. Esas grabaciones se encuentran en el mismo IPC, en el Archive of Traditional Music en Indiana University, y en el Centro de Documentación Musical en Bogotá.

8. Ese punto lo niega el padre Agustín Herrera-Quiñones (comunicación personal, 2017), personaje que tiene más experiencia en la iglesia, pero tuvo menos tiempo con Potes.

9. Un buen resumen de la noción de habitus en el pensamiento de Bourdieu se encuentra en Criado (2009).
} 
(...) para conceptualizar el modo en que los individuos incorporan en su estructura psicológica toda una serie de valores culturales pertinentes a su "condición de clase" y que le identifican, de forma indefectible, como miembro de un determinado grupo social. La profesión, la vestimenta, el uso del lenguaje, el tipo y lugar de la vivienda, el modelo de relación familiar, son una especie de "huella digital" que indica el lugar que ocupan los agentes en el espacio social y el modo en que se posicionan estratégicamente frente a otros agentes (Bourdieu, 1996: 134-135; 1998: 172). Utilizaré esta noción de habitus para mostrar que la ostentación de insignias culturales por parte de la elite neogranadina operaba como una estrategia de construcción social de la subjetividad. (Castro-Gómez, 2005: 81)

Como tal, el concepto de habitus naturaliza un determinado posicionamiento social en forma de un imaginario, un modo de vida, una estructura de pensamiento $\mathrm{y}$ de acción, e inclusive de incorporarlos como un patrón de gustos y de formas de manejar el cuerpo ${ }^{10}$. Así sean construidos socialmente, estos valores se sienten y se entienden como lugares comunes obvios y naturales, y son útiles como códigos o “insignias" para comunicar los valores propios de una determinada clase o posicionamiento social.

Para la teórica Judith Butler (2009), los atributos de las identidades (en el sentido de ostentación de "insignias culturales" que describe Castro-Gómez) no son expresivos de una identidad ya existente, sino "performativos" de identidades en proceso. Una identidad - como la del letrado criollo- se instaura "mediante actos que son internamente discontinuos" (Butler, 2009: 274); se trata entonces de "una identidad construida, una realización performativa en la que el público social mundano, incluidos los mismos actores, llega a creer y a actuar en la modalidad de la creencia (...). [La] base de la identidad (...) es la reiteración estilizada de actos a través del tiempo y no una identidad supuestamente inconsútil" (Butler, 2009:274).

Tanto el habitus como la performativadad son útiles para examinar la intelectualidad colombiana. Se manifiesta, en el planteamiento de Cristina Rojas (2001:140), citado anteriormente, que la autoridad de los letrados criollos "estaba cimentada en su capacidad para producir, circular y valorizar su bien más preciado: las palabras". Vemos lo mismo en el recuento de Malcolm Deas sobre la curiosa y "singular prominencia de gramáticos y filólogos en la vida pública del país" (1993:29) y, refiriéndose a las numerosísimas obras y disputas gramaticales de Rafael Uribe-Uribe, Miguel Antonio Caro, Rufino J. Cuervo, José Manuel Marroquín, Marco Fidel Suárez y Miguel

10. Hay diferencias importantes entre el habitus de Bourdieu y la performance de Butler, que requerirían de un espacio más amplio para desarrollar, pero la forma como Castro-Gómez utiliza el habitus se presta para una lectura Butleriana, donde el habitus se puede "performar". 
Abadía-Méndez, entre otros, concluye que "esta clase de sabiduría y de competencia entre sabios está íntimamente conectada en Colombia con el ejercicio del poder" (Rojas, 2001: 26). Deas muestra estas figuras envueltas en la performance de su maestría de "la gramática, el dominio de las lenguas y de los misterios de la lengua" (Rojas, 2001:28) como maniobras de poder. Cuenta episodios como cuando Marco Fidel Suárez atacó a su rival político, Lorenzo Marroquín, a través de la publicación de una corrección de ciento cincuenta páginas de la novela de su contrincante. El mismo Suárez, hijo ilegítimo de una lavandera, llegó a la presidencia y, según Deas, cuando fue obligado a dimitir por los ataques de Laureano Gómez,

(...) abandonó el poder disparando esta flecha gramatical del parto: "lo único que no perdono en su discurso es el error gramatical (...) el pecado de decir 'ovejos', término desventurado que echa a perder tan brillante oración (...) él todavía no conoce la diferencia entre 'ovejo' y 'cordero'. (Díaz, como se citó en Deas, 1993: 46)

Esa tendencia performativa de la intelectualidad y del mismo poder se hace particularmente notable en el campo del folclor y los estudios de las expresiones populares, donde el papel del pedante abunda, como si entre más dudoso fuera el objeto de indagación intelectual mayor la necesidad del estudioso de fortalecer su autoridad letrada a través de la performance. Por eso puede ser que los trabajos de folclor en Colombia, como plantea el etnomusicólogo Carlos Miñana-Blasco (2000), son trabajos voluminosísimos, logorréicos, grandilocuentes, aparentando una organización sistemática, así carezcan de aparato crítico. Miñana-Blasco confirma el argumento del musicólogo colombiano Egberto Bermúdez, quien, en una mordaz reseña de los intentos de clasificaciones de instrumentos musicales en Colombia, plantea que el esquema clasificatorio del folclorista Guillermo Abadía-Morales "no puede considerarse una clasificación pues está basado en criterios caprichosos, inconsistentes y a veces, totalmente absurdos" (Bermúdez, 1985: 16). La cuestión pertinente no es la de la calidad de trabajos como el de Abadía, sino el hecho de que la performance del método es mucho mejor lograda que cualquier ejercicio de sistematización. Bermúdez (1985:3) es diciente en este sentido cuando sugiere que "la formulación de la clasificación es un fin en sí mismo", un planteamiento que sugiere las operaciones de la performatividad intelectual por parte de los folcloristas.

El poder de esta performatividad no solamente marca la obra de los folcloristas, sino también sus historias de vida. Viendo su biografía, incluso un reconocido folclorista como Guillermo Abadía-Morales (1912-2010) tenía una formación muy parecida a la de Potes: después de estudiar algo de medicina, trabajó como farmacéutico en los Llanos Orientales, donde se interesó en los indígenas y viajó por el 
país aprendiendo lenguas indígenas en las décadas de 1930 y 1940. Su entrada al folclor fue algo casual, como Abadía describió con su acostumbrada ironía:

Volví de las selvas a Bogotá en 1944, andando con botas, barba larguísima y salacot. Un día Cesar Uribe Piedrahita, dueño de un reconocido laboratorio y Kiko Ruíz, el gerente, me vieron. Me reconocieron, me disfrazaron de señor y me contrataron para entrenar vendedores farmacéuticos. También enseñé en el Conservatorio de Música de la Universidad Nacional, Sociología del Desarrollo, es decir Folclorología, especialmente Etnomusicología. Era lo que había aprendido durante mi estancia con las tribus. (Plazas, 2002: 3-4)

Esta notable diferencia en las opciones de trabajo de Abadía y Potes tenía que ver con otros factores, además de los educativos. Abadía venía de una familia de apellidos reconocidos; un tío de su padre, Miguel Abadía-Méndez (otro personaje perfilado en el artículo de Deas), había sido presidente de la República entre 1926 y 1930. Abadía tenía el capital social como hombre blanco de élite que permitió que lo reconocieran y le consiguieran trabajo. De igual manera, no fueron sus estudios, sino la inculcación en el habitus de masculinidad letrada y de clase alta lo que le acreditaba para dar cátedra en la Universidad Nacional sobre "Folclorología" (neologismo muy abadiamoralesco, por su perfume de performatividad letrada).

Potes estaba muy consciente del carácter performativo de la intelectualidad. En su discurso durante el Foro Nacional de Folcloristas en Manizales, en 1975, mostró performatizó- una notable erudición. Soltó palabras en alemán e hizo referencia a la etnobotánica, a la herpetología, a la Rama Dorada de Campbell, al poeta español del siglo XV Juan del Encisa, todo con una fluidez completamente natural y todo, juzgando por la foto incluida, sin zapatos y vestido con su habitual traje de pescador (Potes, 1975).

Había también en su autopresentación como letrado descalzo una irreverencia muy crítica de los juicios de esta intelectualidad performativa. Según Alicia Camacho, su brazo derecho en los grupos culturales por muchos años, el atuendo humilde que vestía Potes fue en parte un experimento social, para ver cómo lo tratarían.

Él se metía descalzo a los museos. Con el pantalón [remangado]. Para que lo tomaran como negro, pues, estúpido. “'Y este campesino que no sabe nada [que hace aquí]?”. Como chimpa. Y entonces, por ejemplo, él llegaba y lo trataban como "¿Y ése quién es? ¿Este qué viene a hacer acá?”. Y entonces [Potes] llegaba por ejemplo a un libro que estaba en alemán. [Decía:] "Señorita me hace el favor y me pasa tal libro", ¿verdad? Se lo pasaban. Y llegaba él: “No, esto no dice nada, esto es pura basura. Páseme otra”, que está, por ejemplo, en italiano. Entonces ya [decían]: "Bueno, ¿y este quién es?” [risas]. Entonces él lo hacía con esa intención para que la gente se equivocara con él. Pero 
con ese hecho ya iba demostrando: yo soy Teófilo R. Potes, yo soy folclorista. (Alicia Camacho, comunicación personal, 2013)

En el país de los presidentes gramáticos, de los Caros y los Cuervos, donde el capital cultural de lo letrado ha sido tan crucial para definir el mismo poder político (Deas, 1993), que un negro descalzo desafiara la distribución del saber no fue una simple broma, sino algo que podría denominarse un "mamagallismo" epistemológico.

\section{"Lo que el pueblo sabe"}

En el mismo discurso que Potes dio a los folcloristas en Manizales, distinguía entre lo que es el folclor en Colombia y lo que debería ser: "Se han confundido el folclor con el volkskunde (...). Aquí se ha hecho volkskunde, es decir se ha hecho lo que se sabe del pueblo, no lo que el pueblo sabe" (Potes, 1975: 14).

La distinción entre los dos es clave en el pensamiento de Potes $^{11}$. A través del volkskunde ("lo que se sabe del pueblo"), se explota "lo que el pueblo sabe", para el beneficio de "personas que no son del pueblo" (Potes, 1975: 14). De ahí surgen las distorsiones y el enriquecimiento de los "filibusteros del folclor" (Potes, 1975: 17), entre los cuales Potes se refiere no tanto a los letrados, sino al comercio del folclor de los "ballets folclóricos" (Potes, 1975:17), presuntamente en el estilo ostentoso y lentejueludo de Sonia Osorio (Parra-Gaitán, 2008).

Pero aún más importante que reconocer las distorsiones de presumir lo que se sabe de la gente, es la insistencia de Potes en el valor de lo que la gente sabe, que es para él un saber tan valioso o, en algunos casos, más valioso que el occidental. Potes (1975) da varios ejemplos en el campo de la curación tradicional:

Se llama simplemente curandero, yerbatero, brujo, vedor, pulsiador, aún ${ }^{12}$ estafador, a un tipo que conoce un secreto de una yerba que actualmente en un laboratorio se convierte en antibiótico para curar (...). Cómo es posible que un curandero sepa, sin estudiar siquiatría, como se cura la locura? Cómo es posible que un hombre que no ha estudiado, que no sabe de la dietética, lleve un hombre a su casa, le formule una yerba y le prescriba una dieta especialísima la cual él mismo controlara? Así logra curar enfermedades que el médico no ha podido curar (...). Pregunto, por qué la ciencia

11. Claramente, anticipa el pensamiento poscolonial y descolonial, y modela algunas de las paradojas famosamente tratadas por Spivak (2011).

12. Los errores ortográficos de la cita corresponden a la redacción hecha por la fuente, ya que se trata de la transcripción de una charla de Potes. 
médica no ha aprovechado esta manantial, esta fuente enorme de conocimientos que tiene el curandero? Es parte del folclor. (15)

Como punto de comparación, es interesante pensar en la experiencia de otro médico vuelto folclorista, Manuel Zapata-Olivella (1990), quien, en su autobiografía ¡Levántate mulato!, cuenta su experiencia como joven médico en una comunidad aislada de la Ciénaga Grande. Describe la yerbatería y curandería de la gente como algo curioso y coloreado, pero al fin y al cabo su reto era desprender la comunidad de eso para acudir a la medicina occidental que practicaba él. O sea, sus compromisos epistemológicos son con Occidente, mientras Potes propone algo más radical.

Con esa noción del folclor como un saber, Potes da una vuelta entera a la estructura de la relación entre el saber occidental y los saberes populares. Si bien un pensador como Castro-Gómez (2005) reconoce que en la historia colombiana es el saber occidental el que disciplina, enmarca, domestica los saberes populares; para Potes (1975), el saber popular es la raíz, inclusive, del saber occidental:

El folclor sigue siendo, a través de los siglos, el súmmum de todas las ciencias humanas. Por donde quiere que uno lo golpee, por donde uno lo toque, resulta una ciencia. La medicina tiene que ver muchísimo con el folclor desde sus comienzos. Aún hoy. La ingeniería, la arquitectura; el léxico; el filólogo, el filósofo, el antropólogo, el etnólogo. Todo mundo tiene que pegarse del folclor, porque el folclor es pueblo. Y desde que sea pueblo, todas las ciencias tienen que desembocar allí, por una u otra razón. Los científicos deben aprovecharlo para devolverlo en beneficio del pueblo que es quien lo ha creado. (16)

Más aún, Potes admitía no solamente que los saberes afropacíficos tenían algo que ofrecer a los saberes metropolitanos/modernos, sino que planteaba la validez del mundo místico a que esos saberes se refieren. No se trataba solamente de que el curandero supiera de plantas con compuestos químicos que el científico no conocía, pero que en un laboratorio apreciaría. Eso sería cuestión de un conocimiento empírico, pero referente al mismo mundo que ocupa el científico. En cambio Potes veía que el curandero sabía de -y actuaba en- otro "universo", de oraciones, de vistas, de secretos, de espíritus.

En nuestra región hay curanderos que practican un ritual que se llama "magina". Exactamente igual al "vudú” haitiano. Un negro cualquiera llegó a un consultorio y le habló al médico de la enfermedad que padece; el médico no entendió lo que él le dijo, le formuló cualquier cosa y decía "ese tipo se muere". El pariente que está ahí dice "no seño, nosotros tenemos un primo que sabe de esa cosa” (...). Llevan al enfermo a la 
casa del curandero. El curandero tiene 6, 7, 9 bastones, de chonta, de marequende, de machare, de chachajo, de chachajillo, porque dice que cada uno de esos árboles tiene un espíritu, el espíritu del árbol (...) [que] cura determinada enfermedad. Entonces hacen un ritual, al cual no entra sino el negro. Toca el bastón, invoca un espíritu y dice "ya llegó, ya llegó”. Y hay que pasarlo allá donde está el enfermo. El enfermo está tendido en el suelo, en una sábana blanca, y en la cabeza tiene una batea llena de agua con un muñequito de balso. Hay un momento en que ese muñeco gira hacia determinado lugar, y todos los asistentes dicen "se cura el enfermo". Yo pregunto, o será el poder mental de esa gente, no será aquella psicosis colectiva, llevada en cierta forma para que el enfermo se alivie? [sic]. El curandero continúa haciendo su ritual. Baña al enfermo. Un tipo que ha estado con una enfermedad gravísima, lo echan al río. Y al otro día está trabajando. (Potes, 1975: 16) ${ }^{13}$

Es más: varias personas recuerdan que Potes sabía vislumbrar y curar heridas espirituales en las personas (Alicia Camacho, comunicación personal, 2013; 2014; Lelys Góngora, comunicación personal, 2017); el mismo Potes, políglota, egresado de colegio exclusivo, practicaba y enseñaba los saberes ancestrales que en el Pacífico suelen llamar "secretos".

Él practicaba lo de las vistas, inclusive con una argolla, la argolla de matrimonio. Con un vaso de agua y una hebra de cabello. Que igual mi mamá lo practicaba. Porque mi mamá aprendió con él (...). También las oraciones. Todo eso, esa clase de secreto. Él era sobandero, curandero. (Lelys Góngora, comunicación personal, 2017)

Lo que Potes propuso, en sus palabras y en sus acciones, era bastante radical. No buscaba solamente valorizar una cosmovisión, sino reconocer todo un cosmos. Si bien rompía con la racionalidad eurocéntrica, lo importante iba más allá de descentralizarla como una forma de ver el mundo -una provocación epistemológica-. Más bien, planteaba otro mundo, poblado de espíritus y mediado por los rituales y los "secretos", y ponía en cuestión qué era la realidad. Es decir, lanzaba una provocación ontológica.

En ese sentido, Potes anticipaba lo que la antropología reciente llamaría el "giro ontológico" (Ruiz-Serna; Del Cairo, 2016). Un reciente resumen del giro ontológico caracteriza el pensamiento del francés Philippe Descola (importante protagonista del movimiento, junto con el brasileño Eduardo Viveiros de Castro): 
(...) al formular las relaciones que los humanos establecen con los no-humanos en términos de ontologías, Descola presupone la existencia de una multiplicidad de realidades y de mundos, superando las tradicionales interpretaciones relativistas que dan por sentada la existencia de una sola y consolidada realidad (naturaleza) a la que se tiene acceso mediante ciertos marcos interpretativos histórica y socialmente situados (cultura). Comprendidas de ese modo, las rutas ontológicas desestabilizan la noción misma de naturaleza, no porque ella no exista sino porque deja de ser la noción estable de una realidad sobre la que se construyen variadas representaciones o visiones. En este sentido disciplinas como la antropología que se han enfocado en comprender el reino del anthropos (Descola y Pálsson, 2001) deben superar esa frontera y enfocarse en la comprensión de los modos de emergencia de distintas naturalezas o realidades. (Ruiz-Serna; Del Cairo, 2016: 196)

Aquí, no se trata de un relativismo multiculturalista educado, donde todas las culturas o las formas de pensar son bonitas, que les permiten a los no-occidentales sus creencias pintorescas. Tampoco se limita al gesto descolonial de plantear una horizontalidad de saberes y conocimientos, o de descentralizar el pensamiento occidental, como propone Castro-Gómez (2005), aunque también lo hace. Propone una multiplicidad ontológica.

El mismo Potes vivía esa multiplicidad. Como hemos visto, era un letrado, un polímata. Si bien se burlaba de la artificialidad del habitus de la intelectualidad, también pasaba las noches escribiendo en alemán, leyendo en alemán y estudiando los "secretos". Es decir, a la vez que tomó el saber moderno/metropolitano muy en serio, también lo hizo con la cosmovisión afropacífica, y vivía en los dos universos.

\section{“Cuando nos quitaron las cadenas, nos encadenaron la mente"}

En la Buenaventura de su época, muchos vieron a Potes como un excéntrico, tendencioso, pero generalmente inofensivo (Engelberto Díaz, comunicación personal, 2014). La pobreza de esa visión refleja más bien los muy limitados marcos conceptuales para entender la política, cultura e intelectualidad afros de ese momento. Al presentarse Potes - políglota, intelectual, innovador-en las calles de Buenaventura con su grupo, había quienes le gritaban: “¡Eso es pa chimpa!”, utilizando un término despectivo para despreciar lo rústico o retrógrado (Alicia Camacho, comunicación personal, 2013).

Es importante notar que la plataforma que Teófilo Potes utilizaba para plasmar su pensamiento y hacer sus provocaciones era el folclor, una disciplina no muy conocida 
por su audacia intelectual o política en Colombia ${ }^{14}$. Pero lo de Potes fue algo bien distinto al folclor de su época: menos nacionalista, menos obsesionado por divisar cuantías raciales para trazar el mestizaje, menos fosilizante a tradiciones que en la Buenaventura de su época seguían vigentes. Si bien el modelo del grupo de danza folclórica ya era un formato establecido en Colombia para los años sesenta, los grupos de Potes no emergieron del concepto nacional de folclor (Birenbaum-Quintero, 2018; Parra-Gaitán, 2008). La genealogía intelectual de la praxis folclórica de Potes fue bastante diferente: no colombiana sino afroamericana.

En este punto, la influencia de la antropóloga y coreógrafa afroestadounidense Katherine Dunham fue clave. Primero, porque su tiempo con ella permitió que Potes conociera varias culturas afrolatinoamericanas, cuando fueron de gira en 1950, dándole a Potes puntos de comparación, como cuando mencionó la espiritualidad haitiana -en la que participaba la misma Dunham- en su descripción del ritual afropacífico. Pero cabe anotar que Potes nunca buscó enmarcar lo afropacífico en esquemas afroahaitianos, afrocubanas o afrobrasileños; nunca buscó explicar los velorios del Pacífico como bembés afrocubanos, o los santos de un arrullo como orishas (Restrepo, 2005). Tal vez, ese compromiso con entender y mostrar lo local en sus propios términos y según sus propias realidades fue aprendido de Dunham también. Ella fue antropóloga de formación académica, y seguramente la forma como ella trabajaba, como relacionaba sus experiencias con los afrodescendientes de otros países en sus montajes dancísticos y sus textos impulsaron en el joven Potes un proceso de reflexión sobre sus experiencias, como inspector, en el Pacífico ${ }^{15}$.

Lo que sí parece claro es que Potes aprendió de Dunham cómo usar la danza como una dramaturgia. La experiencia de acompañar la obra Southland habría sido clave. Esa obra, la más polémica de Dunham, utilizó técnicas del teatro ruso y la estética del "ballet trágico" de Diaghalev, mezclando danza con teatro. Representaba el linchamiento de un hombre negro falsamente acusado de violar a una mujer blanca, tema que estaba en el aire por unos casos contemporáneos en Estados Unidos (Clark, 2005: 335). En la obra, la primera parte cuenta esa historia; la segunda parte muestra el duelo colectivo de la comunidad del afrodescendiente linchado, repleto de elementos culturales. La forma de danza-teatro y el contenido político de Southland parecen haber quedado con Potes también; su influencia en la dramaturgia de La Mina es evidente, siendo una obra de danza-drama con secciones

14. El presente artículo no se presta para una explicación comprensiva de la historia intelectual del folclor en Colombia. Para ampliar este tema, ver Birenbaum-Quintero (2018), Caicedo-Ortiz (2013), Echeverri (1997), Miñana-Blasco (2000), Ochoa-Gautier (2006), Silva (2005; 2006), Valderrama (2013a; 2013b), Wade (2000) y Zapata-Cortés (2009).

15. Sobre la etnografía de Dunham, ver Durkin (2011). 
múltiples, representando una rebelión de esclavizados en Iscuandé en el siglo XIX, después de que el esclavizado José Domingo muere por trabajo excesivo y maltratos. Se dramatiza su velorio y su entierro, al final del cual sus compañeros matan a los esclavistas y huyen.

Así como retaba las imágenes de la intelectualidad y la misma ciencia, Potes también jugaba con los limitados conceptos "políticos" de la época, y con las posibilidades políticas del arte. El mismo Potes describió la recepción en Bogotá de su obra maestra:

Yo presenté "La Mina" en 1961 en el Palacio de la Carrera. Era presidente el Dr. Alberto Lleras Camargo. La presenté en las calles de Bogotá y me metieron a la cárcel. Hubo una pelotera tremenda. Que eso era comunista. Después volví al Palacio Presidencial a presentar La Mina y le hice esta pregunta al Dr. Lleras: por qué le gustó La Mina? Dijo, que porque es muy hermosa. Le dije, y qué es lo que tiene de comunismo, socialismo (...). No serán las bofetadas que le da el amo al negro José Domingo y cuando éste le dice al hijito: "Hijo tengo que volver otra vez al trabajo; voy a la mina fatal". Le dice: "Taita, ¿y el pecho de tu amo no se condolerá?". Le dice, "hijo, jel pecho de los blancos no se conduele jamás!". Va a la mina y no vuelve. El Presidente dijo, allí no hay comunismo, ¿quién te dijo eso? Pues me van a llevar a la cárcel por eso, le dije, aquí tengo la boleta. Él intervino, pagué solo un día de cárcel y al otro día me echaron a la calle. (Potes, 1975: 17-18) 16

El mensaje político de La Mina -resistencia negra a las instituciones y lógicas de la supremacía blanca- es claro y, en el travieso pero inequívoco relato de Potes, bien provocativo. Hace un guiño tanto al juicio superficial del presidente (hermoso y, por lo tanto, inofensivo) como a la reacción de la policía bogotana, según la cual una política racial era legible solamente en referencia a la lucha entre el comunismo y el capitalismo en América Latina, en época de la Guerra Fría ${ }^{17}$.

Visto en conjunto, el trabajo de Potes fue una labor de concientización étnica, una propuesta, en el fondo, política: "darle una orientación al hombre negro para que aprenda a valorarse, a querer defender su pueblo" (Alicia Camacho, comunicación personal, 2014). Esa labor no fue fácil. Hay que recordar que para esa época (y todavía, en algunos sectores) lo afropacífico no se entendía como una cultura alternativa al pensamiento euro-moderno, sino precisamente una falta de cultura,

16. Los errores ortográficos de la cita corresponden a la redacción hecha por la fuente, ya que se trata de la transcripción de una charla de Potes.

17. El sociólogo Carlos A. Valderrama sugiere que las referencias a los "negros" se habrían entendido en términos gaitanistas, como referencia a las clases populares radicalizadas, generalmente hablando. 
un atavismo que se resistía a civilizarse, un papel en blanco sobre el cual todavía no se habían podido inscribir los patrones de la civilización (Hanchard, 2001). Al presidente le pareció bonito; el rechazo fue sobre todo por parte de los profesionales y la clase media negros de Buenaventura. No solamente chiflaban a Potes y su grupo en la calle, hasta destruyeron los quioscos culturales frente al parque del malecón donde Potes ofrecía demostraciones culturales todos los domingos.

Recuerda Alicia Camacho (comunicación personal, 2014):

[Potes] sufría mucho, sentía mucha tristeza por dentro (...) al verse rechazado por su propia gente. Y lo que más le dolía a él, los llamados intelectuales, que le gritaban: “¿No les da vergüenza? ¡Eso es de chimpa!” (...), [que] le tumbaban los quioscos (...). [Potes quería] tener algo turístico para mostrar, que no ha habido aquí. Y nadie le daba importancia a eso.

Para Potes, lo que hacía falta era un autoconcepto por parte de los mismos afroporteños, los que quedaron desarraigados en la búsqueda para avanzar, en términos de la euro-modernidad. Habían aprendido a odiar lo propio, y eso, como solía decir, tenía al negro encadenado con unas cadenas mentales más fuertes que las de la esclavitud. Entonces, su propósito fue inspirar un sentido de pertenencia. Fue una labor y una lucha netamente políticas. Me dijo con emoción su discípula Alicia Camacho (comunicación personal, 2014):

El negro, si no ama a su cultura, es enemigo del negro. Claro, es enemigo de él mismo. Hay que amarse por dentro, ser negro por dentro, llevar lo negro por dentro, en el estómago (...). Tanto Teófilo como mi persona teníamos el concepto que este trabajo era un trabajo político. Es que es una lucha política, imponer un patrimonio cultural. ¡Eso es política! Por ejemplo, ¿por qué montar La Mina ahí? Para él La Mina era eso (...). Porque mostrar que nosotros somos, que no venimos del continente bruto, que no éramos los animales salvajes. Eso es una lucha política, Michael. Hay que ser negro por dentro. Ahí está el contenido político (...). Es una lucha política. La vida es política. Toda lucha es política. No politiquería, pero sí era política. Eso era Teófilo Roberto Potes. Que Dios lo tenga en la gloria y perdone sus pecados. A mí me hace mucha falta. Todo el mundo tiene que morirse, pero ojalá Dios le hubiera dado más tiempo. Me acuerdo y me da ganas de llorar. Yo sé que él sufrió mucho. Cuando uno piensa en una forma diferente, que uno tiene un pensamiento sano, se gana muchos enemigos gratuito[s], que quieren destruirlo a uno de cualquier forma, y así de esa forma querían destruir a Teófilo (...). Desdichadamente, nosotros era mejor que estuviéramos encadenados, ¿oyó? Porque como decía Teófilo, y así es, cuando teníamos cadena, la mente era libre, pero cuando nos quitaron las cadenas, hicieron un trabajo bien hecho. ¿Qué fue? Encadenarnos mentalmente. Y son las peores cadenas que puede tener el hombre. Cuando usted mentalmente no piensa por sí solo sino que piensa lo que otro quiere que piense. 


\section{Hacía una intelectualidad potesiana}

Hoy en día, el recuerdo de Teófilo Potes está algo atenuado. Un colegio en Buenaventura lleva el nombre, así como la biblioteca del Instituto Popular de Cultura en Cali. Existe un retrato del maestro, no particularmente fiel a su rostro, entre los personajes representados en el gigantesco mural que adorna una pared externa del Centro Administrativo Distrital en Buenaventura, y otro, más pequeño pero mejor, por el maestro Sarria, en el colegio que lleva su nombre. En el año 2017, el centenario de su natalicio pasó sin conmemoraciones.

Pese a la falta de reconocimientos oficiales, las profundas huellas que Potes dejó en el Pacífico siguen vigentes. Los que mejor entienden su legado son los que lo heredaron, los porteños que pasaron por sus manos siendo sus estudiantes o colaboradores. No es casual que entre esas personas se encuentren no solamente bailarines, coreógrafos, músicos, decimeros y artesanos -es decir, personas que trabajan en el nicho de la cultura-, sino también clérigos, sindicalistas, novelistas, políticos y hasta revolucionarios (Medardo Arias-Satizábal, comunicación personal, 2017; Alicia Camacho, comunicación personal, 2013; Engelberto Díaz, comunicación personal, 2014; Agustín Herrera, comunicación personal, 2017; Fabio Caicedo, comunicación personal, 2014). Lo que sí tienen en común es haber asumido su identidad como mujeres y hombres negros del Pacífico, pero sin quedar relegados ni al pasado ni al contexto rural, siempre en diálogo, como el mismo Potes, con la modernidad. Eso es natural para los alumnos de una persona como Potes, que encarnaba las contradicciones de ser un intelectual afropacífico.

Potes conocía de primera mano las varias culturas afroamericanas, mas su postura afrocentrista no hizo que se desprendiera del rinconcito de la diáspora africana que es el Pacífico Sur colombiano, y que, siendo un nacionalista cultural afro que se enfrentó con la desarraigada élite negra de su momento, abogaba por un despertar político basado en el autoconocimiento cultural, a la vez que sus labores culturales se malentendían como pintoresco folclorismo. Potes, bien leído en las ciencias, también practicaba los saberes místicos y ancestrales, las oraciones, las vistas y los secretos.

Hoy en día, con el surgimiento de la cultura, la política y la estética afro en el país, vale la pena volver a considerar la vida, obra y pensamiento -sobre lo político que es la cultura, sobre una intelectualidad afro de naturaleza híbrida, sobre la horizontalidad ontológica de los mundos pacífico y eurocientífico- de su precursor. La respuesta a la pregunta de quién fue Teófilo Roberto Potes es también la respuesta a las posibilidades de lo que puede ser la intelectualidad afrocolombiana. 


\section{Referencias}

\section{Fuentes primarias}

Brandt, Max (1973). Notas de campo (trad. Michael Birenbaum Quintero). Buenaventura: Banco de la República.

\section{Fuentes secundarias}

Alberto, Paulina L. (2011). Terms of Inclusion: Black Intellectuals in Twentieth-Century Brazil. Chapel Hill: University of North Carolina Press.

Andrews, George Reid (1991). Blacks and Whites in São Paulo: 1888-1988. Madison: University of Wisconsin Press.

Arboleda-Quiñonez, Santiago (2011). Le han florecido nuevas estrellas al cielo: suficiencias intimas y clandestinización del pensamiento afrocolombiano (Tesis doctoral). Área de Letras y Estudios Culturales, Universidad Andina Simón Bolívar, Quito.

Bermúdez, Egberto (1985). Reseñas bibliográficas. Revista Colombiana de Investigación Musical, $1(1), 104$.

Bermúdez-Escobar, Isabel Cristina (2007). El regeneracionismo decimonónico en María. En Jorge Isaacs, el creador en todas sus facetas: memorias del primer Simposio Internacional (pp. 243-252), editado por Darío Henao Restrepo. Cali: Universidad del Valle.

Birenbaum-Quintero, Michael (2018). Rites, Rights, and Rhythms: A Genealogyof Musical Meaning in Colombia's Black Pacific. New York: Oxford University Press.

Bourdieu, Pierre (1996). Cosas dichas. Barcelona: Gedisa.

Bourdieu, Pierre (1997). Razones prácticas sobre la teoría de la acción. Barcelona: Anagrama.

Bourdieu, Pierre (1998). La distinción. Criterio y bases sociales del gusto. Madrid: Taurus.

Butler, Judith (2009). El género en disputa. El feminismo y la subversión de la identidad. México: Paidós.

Caicedo-Ortiz, José Antonio (2013). A mano alzada: memoria escrita de la diáspora intelectual afrocolombiana. Popayán: Sentipensar.

Camacho-Garcés, Alicia; Camacho, Mauricio; Birenbaum-Quintero, Michael; Hurtado, Herbert (2014). Alicia Camacho Garcés Interview Transcript. Recuperado de https://open. bu.edu/handle/2144/26722

Castro-Gómez, Santiago (2005). La hybris del punto cero. Ciencia, raza e ilustración en la Nueva Granada (1750-1816). Bogotá: Pontificia Universidad Javeriana. 
Chasteen, John Charles (1996). Introduction. En The Lettered City (pp. vii-xiv). Raleigh, NC: Duke University Press.

Clark, VèVè A. (2005). Performing the Memory of Difference in Afro-Caribbean Dance: Katherine Dunham's Coreography, 1938-1987. Kaiso! Writings by and About Katherine Dunham, editado por Vèvè A. Clark y Sara E. Johnson. Madison: University of Wisconsin Press.

Criado, Enrique Martín (2009). Habitus. En Diccionario crítico de ciencias sociales. Terminología cientifico-social (p. 1427-1439), editado por Román Reyes. Madrid/México D.F.: Plaza y Valdés.

Deas, Malcolm (1993). Miguel Antonio Caro y amigos: gramática y poder en Colombia. En Del poder y la gramática y otros ensayos sobre historia, política y literatura colombianas (pp. 25-60). Bogotá: Tercer Mundo.

Descola, Phillipe (2012). Más alla de naturaleza y cultura. Buenos Aires: Amorrortu.

Durkin, Hannah (2011). Dance Anthropology and the Impact of 1930 os Haiti on Katherine Dunham's Scientific and Artistic Consciousness. International Journal of Francophone Studies, 14, 1-2.

Echeverri, Marcela (1997). El proceso de profesionalización de la antropología científica en Colombia: un estudio de caso en torno a la difusión de las ciencias y su institucionalización. Historia Crítica, 15: 67-79. https://doi.org/10.7440/histcrit15.1997.04

Hanchard, Michael (2001). Afro-Modernity: Temporality, Politics, and the African Diaspora. En Alternative Modernities (pp. 272-298), editado por Dilip Parameshwar Gaonkar. Durham, NC: Duke University Press.

Losonczy, Anne-Marie (2006). La trama interétnica. Ritual, sociedad y figuras de intercambio entre los grupos negros y Emberá del Chocó. Bogotá: Instituto Colombiano de Antropología e Historia.

Miñana-Blasco, Carlos (200o). Entre el folklore y la etnomusicología. 60 años de estudios sobre la música popular tradicional en Colombia. A Contratiempo, 11, 36-49.

Muñoz, Catalina (2014). "A Mission of Enormous Transcendence”: The Cultural Politics of Music during Colombia's Liberal Republic, 1930-1946. Hispanic American Historical Review, 94(1), 77-105.

Ochoa-Gautier, Ana María (2006). Sonic Transculturation, Epistemologies of Purification and the Aural Public Sphere in Latin America. Social Identities, 12(6), 803-825.

Parra-Gaitán, Raúl (2008). Algunas reflexiones sobre la danza tradicional. En Danza, tradición y contemporaneidad: reflexiones de los maestros de los procesos de formación a formadores y diálogo intercultural (pp. 21-33), editado por Natalia Orozco; Sandra Gómez Cabarcas. Bogotá: Ministerio de Cultura. 
Plazas Rodríguez, Ángela (2002). Guillermo Abadía Morales. Recuperado de www.colombiaya. com/escritores/guillermoabadiamorales.pdf

Potes, Teófilo Roberto (1975). Intervención en el primer Foro Nacional de Folkloristas. Aleph, 1O(1): 13-18.

Rama, Ángel (1984). La ciudad letrada. Montevideo: Arca.

Restrepo, Eduardo (2005). Entre arácnidas deidades y leones africanos: contribución al debate de un enfoque afroamericanista en Colombia. En Políticas de la teoría y dilemas de los estudios de las colombias negras (pp. 77-118), editado por Eduardo Restrepo Uribe. Popayán: Universidad del Cauca.

Rojas, Cristina (2001). Civilización y violencia. La búsqueda de la identidad en la Colombia del siglo XIX. Bogotá: Norma.

Ruiz-Serna, Daniel; Del Cairo, Carlos (2016). Los debates del giro ontológico en torno al naturalismo moderno. Revista de Estudios Sociales, 55, 193-204.

Silva, Renán (2005). República liberal, intelectuales y cultura popular. Medellín: La Carreta.

Silva, Renán (2006). Sociedades campesinas, transición social y cambio cultural en Colombia. La Encuesta Folclórica Nacional de 1942: aproximaciones analíticas y empíricas. Medellín: La Carreta.

Sommer, Doris (1991). Foundational Fictions: The National Romances of Latin America. Berkeley: University of California Press.

Spivak, Gayatri Chakravorty (2011). ¿Puede hablar el subalterno? Buenos Aires: El Cuenco de Plata.

Valderrama, Carlos A. (2013a). Black Politics of Folklore: Expanding the Sights and Forms of Politics in Colombia (Tesis de maestría). Departamento de Sociología, Facultad de Ciencias Sociales y del Comportamiento, Universidad de Massachusetts, Amherst.

Valderrama, Carlos A. (2013b). Folclore, raza y racismo en la política cultural e intelectual de Delia Zapata Olivella: El campo político-intelectual afrocolombiano. Revista CS, 12, 259296. https://doi.org/10.18046/recs.i12.1674

Valis-Hill, Constance (1994). Katherine Dunham's “Southland”: Protest in the Face of Repression. Dance Research Journal, 26(2), 1-10.

Wade, Peter (2000). Music, Race and Nation: Música Tropical in Colombia. Chicago: University of Chicago Press.

Zapata-Cortés, Diana Catalina (2009). Entre danzas, tambores y rezos: somos colombianos. Representaciones del "negro" en la obra folclórica de Deliay Manuel Zapata Olivella (1950-1970) (Trabajo de grado). Facultad de Ciencias Sociales, Departamento de Historia, Universidad de los Andes, Bogotá.

Zapata-Olivella, Manuel (1990). ¡Levántate mulato! Bogotá: Rei Andes. 